\title{
PENGARUH DIGITALISASI DALAM EFEKTIFITAS PENGELOLAAN KEARSIPAN DOKUMEN KEPESERTAAN BPJS KETENAGAKERJAAN
}

\author{
Mau'izah dan Damrus \\ Universitas Teuku Umar, Indonesia \\ Email: mauizah235@gmail.com dandamrus@utu.ac.id
}

\begin{abstract}
Abstrak
Dalam setiap perkantoran maupun perusahaan, baik swasta maupun pemerintahan memerlukan penyimpanan, pengolahan, pencatatan dokumen gunanya untuk menyimpan data-data setiap kantor maupun perusahaan dengan sistem tertentu yang dapat dipertanggung jawabkan. Kegiatan teresebut dinamakan dengan istilah sistem administrasi kearsipanPenelitian ini bertujuan untuk mengetahui pengaruh digitalisasi dalam efektifitas pengelolaan kearsipan dokumen kepesertaan BPJS Ketenagakerjaan Cabang Meulaboh. Metode penelitian ini adalah kualitatif deskriptif. Adapun hasil penelitian ini menunjukkan bahwa dikantor BPJS dalam mengelola arsip menggunakan tiga sistem yaitu sistem manual, sistem digitalisasi dan sistem terbaru. Penyimpanan arsip sangat penting bagi kelancaran kegiatan organisasi yang berguna sebagai sumber informasi dan pusat ingatan. Sayangnya apresiasi terhadap arsip masih sangat rendah sehingga tidak dikelola dengan baik. Digitalisasi sangat berhubungan dengan kelestarian arsip. Proses digitalisasi arsip di kantor BPJS cabang Meulaboh memiliki kendala-kendala dalam mendigitalisasi arsip seperti keterbatasan sumber daya manusia yaitu jumlah staf yang melakukan pendigitalisasian arsip yang masih kurang. kerusakan alat scanner yang harus segra diperbaiki, dan melakukan perbaikan terhadap pemeliharaan web yang sering terjadi, yang memprengaruhi proses kerjanya.
\end{abstract}

Kata Kunci: Kantor BPJS; Digitalisasi; Efektifitas; Dokumen

\section{Abstract}

In every office or company, both private and government require storage, processing, recording documents useful to store data of each office and company with certain systems that can be accounted for. This activity is called the archiving system. This study aims to determine the effect of digitalization on the effectiveness of archive management of BPJS Ketenagakerjaan membership documents in the Meulaboh Branch. This research method is descriptive qualitative. The results of this study indicate that the BPJS office in managing archives uses three systems, namely the manual system, the digitization system and the latest system. Archival storage is very important for the smooth running of organizational activities that are useful as a source of information and a memory center. Unfortunately, the appreciation of archives is still very low so it is not managed properly. Digitization is closely related to archive preservation. The process of digitizing archives at the BPJS Meulaboh branch office has problems in digitizing archives, such as limited human resources, namely the 
number of staff who digitize archives is still lacking. scanner tool malfunction that must be repaired immediately, and make improvements to web maintenance that often occurs, which affects its work process.

Keywords: BPJS Office; Digitization; Effectiveness; Documents

Diterima: 12-12-2021 Direvisi: 12-01-2022 Diterbitkan: 20-01-2022

\section{Pendahuluan}

Arsip merupakan suatu dokumentasi yang dapat berfungsi sebagai sumber data dan informasi bagi suatu organisasi ataupun orang yang telah mengarsipkannya. Arsip juga dapat diartikan sebagai suatu pusat ingatkan bagi mereka yang menyimpannya (diarsipkan). Secara umum arsip hanya dilihat sebagai tumpukan kertas yang tidak bernilai, namun jika dilihat lebih dalam maka arsip merupakan asset penting yang sangat bernilai, dapat dijadikan alat bukti, maupun pengingat waktu baik masa lampau (sejarah), sekarang dan masa mendatang. Dokumen arsip akan terus bertambah seiring dengan berjalannya waktu, dimana jika hal ini tidak diikuti dengan sistem kerja yang baik, peralatan yang tidak memadai dan kurangnya tenaga ahli yang kompeten dalam bidangnya maka akan memicu permasalahan yang dapat megakibatkan kerugian dalam bentuk biaya dan waktu (Prapita Imadianti, 2010).

Berdasarkan Keputusan Presiden Republik Indonesia Nomor 105 Tahun 2004 mengenai pengelolaan arsip tepatnya pada bab III tentang Jaringan Informasi Kearsipan Nasional Pasal 35 dijelaskan bahwa JIKN merupakan pusat jaringan dan anggota jaringan, ANRI berperan sebagai pusat jaringan dan anggota jaringannya merupakan Lembaga Kearsipan Propinsi dan Lembaga Kearsipan Kabupaten/Kota hal ini dapat diadopasi oleh lembaga lainnya.

Dalam setiap perkantoran maupun perusahaan, baik swasta maupun pemerintahan memerlukan penyimpanan, pengolahan, pencatatan dokumen gunanya untuk menyimpan data-data setiap kantor maupun perusahaan dengan sistem tertentu yang dapat dipertanggung jawabkan. Kegiatan teresebut dinamakan dengan istilah sistem administrasi kearsipan (Bahri dan Nisa, 2017). Pengelolaan arsip dapat disesuaikan dengan kebijakan suatu perusahaan sesuai dengan manajemen arsip di perusahaan tersebut. Mengingat peranan arsip sangat penting dalam sebuah organisasi maupun perusahaan, sistem dalam mengaplikasikan atau yang mengumpulkan data-data administrasi dalam perusahan haruslah baik dan benar, karena jika pengelolaan datadata administrasi dalam perusahaan kurang baik maka akan menimbulkan perusahaan sulit untuk memperoleh atau menerima informasi baik dari sebuah perusahaan. Suatu organisasi maupun perusahaan itu terbentuk karena adanya pengaruh dari beberapa aspek untuk mewujudkan visi, misi, dan tujuan agar organisasi maupun perusahaan berjalan dengan baik. Arsip merupakan sumber informasi yang sangat berpengaruh dalam sebuah oranisasi maupun perusahaan karena arsip berisi informasi tentang fungsi dan kegiatan dari organisasi tersebut (Faruk dan Almahdi, 2020). 
Badan Penyelenggara Jaminan Sosial (BPJS) Ketenagakerjaan adalah hasil perubahan atau anak perusahaan dari PT jaminan sosial tenaga kerja (JAMSOSTEK). Jaminan ini di lakukan pada 2014 lalu, mengacu pada Undang-undang (UU) No 4 tahun 2011 tentang BPJS. BPJS Ketenagakerjaan sendiri merupakan suatu lembaga Negara yang menghimpun iuran dari pekerja, dimana dana itu selanjutnya di kelola sebagai jaminan kematian, jaminan kecelakaan kerja, jaminan pensiunan hingga jaminan hari tua. Sebagai lembaga Negara yang besar, yang menampung seluruh iuran dari para pekerja seluruh Indonesia, maka setiap kantor BPJS Ketegakerjaan harus mencatat setiap dokumen guna melengkapi syarat untuk terbentuknya administrasi yang di namakan sebagai arsip (Santika, dkk, 2018).

Undang-Undang nomor 43 tahun 2009 Pasal 1). Penyelenggaraan kearsipan sangat penting diberlakukan pada seluruh lembaga baik di lembaga swasta, Negara, dan BUMN. Salah satunya Badan Penyelenggara Jaminan Sosial (BPJS) Ketenagakerjaan, banyak arsip dinamis yang masuk dan disimpan stiap harinya. BPJS Ketenagakerjaan merupakan salah satu badan penyelenggara jaminan sosial yang memenuhi perlindungan dasar bagi tenaga kerja. Arsip pada lembaga ini dapat berbagai macam mulai dari arsip biodata anggota atau peserta BPJS hingga arsip klaim peserta jaminan sosial. Adapun bentuk Arsip klaim adalah Jaminan Kecelakaan Kerja (JKK), Jaminan Hari Tua (JHT), dan Jaminan Kematian (JKM). BPJS Ketenagakerjaan ini melayani masyarakat baik yang berbentuk individu (perorangan) maupun bentuk perseorangan (Mellaty, 2015).

Dokumen merupakan bagian dari arsip itu sendiri. Secara sederhana dapat dikatakan bahwa semua arsip adalah dokumen, tetapi tidak semua dokumen adalah arsip. Dokumen yang digunakan oleh individu atau badan hUkum menjalankan kegiatan dan fungsinya di sebut arsip dinamis atau arsip (Bahri dan Nisa, 2017).

Setelah memahami pengorganisasian arsip, pihak staf arsip juga harus memiliki pemahaman tentang asas pengorganisasian yang akan di pilih dalam pengelolaan arsiparsip yang dimiliki pihak perusahaan atau lembaga (sentralisasi, desentralisasi, dan gabungan). Bagian arsip pada kantor BPJS Ketenagakerjaan Cabang Meulaboh adalah meliputi bagian yang mengelola dan menyajikan arsip yang salah satunya adalah arsip kepesertaan, seperti arsip Jasa Kontruksi (JAKON), arsip Penerima Upah (PU), arsip Bukan Penerima Upah (BPU) (Kuswanto dan hartarti, 2019).

Saat ini, di tempat penulis melaksanakan penelitian staf admin sering kerepotan dalam menyusun data-data berupa dokumen kepesertaan yang dari hari kehari semakin bertambah banyak dan membuat Fillingcabinet menjadi penuh tidak beraturan. Penulis sedikit memberikan solusi yang seharusnya di lakukan staf bagian arsip dalam menyelesaikan masalah tersebut yaitu, semakin meningkatnya jumlah peserta dengan bertambahnya jumlah dokumen, staf bagian arsip memisahkan dokumen. misalkan dokumen dari 5 tahun terakhir di pisahkan dengan dokumen 10 tahun terakhir agar staf bagian arsip tidak kesulitan dalam mencari berkas yang diperlukan karena seiring bertambahnya dokumen setiap hari (Kuswantoro dan Hartarti, 2019). 
Berdasarkan uraian latar belakang diatas, fokus penelitian saya ini adalah bagaimana pengaruh digitalisasi dalam efektifitas pengelolaan kearsipan dokumen kepesertaan BPJS Ketenagakerjaan Cabang Meulaboh?

\section{Metode Penelitian}

Adapun metode penelitian yang diterapkan dalam penelitian ini adalah pendekatan kualitatif. Metode ini digunakan untuk mengungkapkan berbagai fenomena secara holistik kontekstual, dengan data yang sudah dikumpulkan dari lapangan secara natural dimana peneliti berfungsi sebagai instrumen kunci. Terkait dengan penelitian ini peneliti mencari data selengkap mungkin yang berkaitan dengan pengaruh digitalisasi dalam efektifitas pengelolaan kearsipan dokumen kepesertaan BPJS Ketenagakerjaan. Peneliti menggunakan teknik pengumpulan data dengan data primer dan sekunder yaitu data dari beberapa pihak yang ada di BPJS Ketenagakerjaan yang dianggap memiliki kompetensi dalam menjawab pertanyaan dan rumusan masalah penelitian. Untuk data sekunder peneliti menggunakan berbagai jurnal, literatur, textbook dan referensi terkait untuk landasan teori dan memperoleh hasil penelitian.

\section{Hasil dan Pembahasan}

\section{A. Karakteristik Responded Menurut Usia}

BPJS Ketenagakerjaan merupakan badan hukum public yang bertanggung jawab kepada presiden dimana BPJS Ketenagakerjaan memberikan perlindungan kepada seluruh pekerja Indonesia baik sektor formal maupun informal dan orang asing yang bekerja di Indonesia sekurang-kurangnya 6 bulan. Perlindungan yang diberikan berupa: Jaminan Kecelakaan Kerja (JKK), Jaminan Kematian (JK), Jaminan Hari Tua (JHT) dan jaminan Pensiunan (JP). Tujuan pada penelitian ini adalah deskriptif dengan metode interview methode. Responded pada penelitian ini adalah total seluruh staf yang bertugas pada kearsipan dokumen (Bahri dan Nisa, 2017).

Hasil dari penelitian ini sebanyak 5 orang responded keseluruhannya laki-laki. Diagnosis dari total jumlah staf yang bertugas bagian kearsipan dokumen, sebagian besar umurnya 27 tahun dan 3 orang lainnya berumur $>30$ tahun.

\section{B. Tanggapan Responded Terhadap Kinerja}

Menurut informan utama, sebagai staf arsip yang memiliki jabatan staf inti pada kantor tersebut, menyampaikan bahwa minimnya kepedulian karyawan terhadap kearsipan di kantor BPJS Ketenagakerjaan Cabang Meulaboh. Dikarenakan kurangnya kesadaran yang menganggap bahwa kearsipan di kantor tersebut tidak terlalu penting. Hal ini langsung di nyatakan oleh pihak staf arsip itu sendiri, berikut pernyataannya:

"Jadi begini, terkait dengan masalah arsip yang jadi kendalanya itu dari pihak karyawan itu sendiri yang kurangnya kesadaran dalam kearsipan. Contohnya setelah mereka menyiapkan berkas, berkasnya itu dibiarkan begitu saja. padahal jika dilihat segi kegunaannya arsip berfungsi salah satunya yaitu sebagai pusat ingatan." 
Dari hasil wawancara diatas, peneliti menilai bahwa kinerja karyawan belum mencapai tahap yang diinginkan, seperti kesadaran akan pentingnya arsip. Menurut informan kedua, yang memiliki jabatan sebagai ketua bidang kepesertaan menyampaikan proses pengarsipan dokumen di BPJS Ketenagakerjaan Cabang Meulaboh ini mengikuti aturan yang sudah diterapkan oleh pihak manajemen, berikut pernyataannya:

"Kalau dari proses pengarsipan dokumen ini, disini kami memang sudah diatur oleh pihak manajemen itu sendiri, kami hanya mengikuti sesuai dengan aturan tersebut, jadi prosesnya untuk memudahkan arsip, karena sudah tertata atau sudah tersusun sesuai dengan aturannya."

Dari hasil wawancara diatas, peneliti menilai bahwa di BPJS Ketenagakerjaan Cabang Meulaboh ini tidak perlu menerapkan proses pengarsipan sendiri karena memang sudah ada peraturannya sendiri.

Menurut informan ketiga, yang memiliki jabatan sebagai ketua bidang pelayanan menyampaikan bahwa cara efektif dalam pengarsipan dokumen yaitu jangan menundanunda atau jangan sampai menumpuk. Penyataannya:

"Selama kami disini cara efektif yang dilakukan dalam pengarsipan dokumen ini yaitu dengan cara jangan menunda-nunda atau jangan sampai menumpuk, jadi setiap berkas yang udah siap itu langsung diarsipkan dalam waktu itu juga."

Dari hasil wawancara diatas, peneliti menilai bahwa mereka melalukan dengan caranya sendiri dengan bergerak cepat atau mengejar target. Menurut informan keempat, yang mempunyai jabatan sebagai ketua umum menyampaikan bahwa dikantor BPJS Ketenagakerjaan Cabang Meulaboh dalam mengelola arsip, mereka memakai dua sistem, yaitu sistem manual dan sistem digitalisasi.

Pengelolaan arsip peserta jaminan sosial sudah dilakukan dengan cukup baik, yaitu meliputi kegiatan penciptaan, penyimpanan, pengolahan, perawatan, dan sistem temu kembalinya. Untuk penyusutan belum dilakukan dengan baik karena belum pernah dilakukan. Pengolahan arsip klaim jaminan sosial meliputi proses verifikasi arsip, scanner dan input informasi arsip (proses digital), memasukan dalam box arsip, dan memberi cap pada box (sistem manual). Sistem penyimpanan yang dipakai adalah gabungan sistem subjek dan kronologis.

Tetapi sekarang sistem itu menjadi tiga dengan menambah sistem arsip terbaru yaitu dengan cara aplikasi online, berikut pernyataannya:

"Untuk mengelola dokumen arsip ini kami pertamanya memakai dua sistem, pertamanya sis manual yaitu sistem proses pengimputan, membuat katalog dan membuat daftar arsip, dan yang kedua sis digitalisasi yaitu untuk arsip yang keluaran lama sampai yang sekarang dengan cara melakukan scan."

Dari wawancara diatas, dapat dinilai bahwa mereka menggunakan tiga system yaitu sis manual, digitalisasi dan sis terbaru. Menurut informan kelima, yang mempunyai jabatan ketua bidang keuangan menyatakan jumlah staff yang bertugas dalam pengarsipan itu totalnya ada 5 , staff inti $=1$ orang, dan tambah dari 4 bidang masing-masing 1 orang. Berikut pernyataanya: 
"Jadi staff yang bertugas di arsip itu ada staff inti 1 orang, terus di BPJS

Ketenagakerjaan ini ada 4 bidang, jadi dari 4 bidang ini diambil perbidang 1 orang, total yang bertugas dalam pengarsipan yaitu ada 5."

Dari hasil wawancara diatas dapat dinilai bahwa orang yang bertugas di bagian arip itu ada 5 orang, petugas yang utama ialah petugas sebagai staff inti dan seterusnya ialah petugas perwakilan dari bidang masing-masing.

\section{Lingkungan Kerja}

Lingkungan kerja ialah salah satu aspek penting bagi kinerja karyawan karena lingkungan kerja sangat berpengaruh berat dalam kinerja karyawan. Jadi jika lingkungan kerjanya aman dan nyaman itu merupakan salah satu cara agar kinerja karyawan meningkat (As'ad, 2012).

Lingkungan kerja karyawan di kantor BPJS Ketenagakerjaan Cabang Meulaboh tidak terlalu baik dikarenakan karyawan di BPJS hampir semua jauh dari tempat kerja. Lingkungan kerja yang kondusif akan dapat meningkatkan motivasi pegawai, perilaku serta kepuasan kerja (Nzewi \& Hope 2018)

\section{Motivasi Kerja}

Menurut Santika et al, (2018) Motivasi adalah suatu faktor yang mendorong seseorang untuk melakukan suatu aktivitas tertentu. Oleh karena itu, motivasi sering kali diartikan pula sebagai faktor pendorong perilaku seseorang.

Menurut Hasibuan dkk (2013) motivasi adalah suatu kondisi kejiwaan, sikap dan mental seseorang yang memberikan energi, mendorong kegiatan (moves) dan dapat berdampak pada perilaku seseorang kearah positif untuk mencapai kebutuhan yang memberi kepuasan atau mengurangi ketidakseimbangan.

Hubungan kerja di BPJS Ketenagakerjaan Cabang Meulaboh sangat menarik dan unik sesuai yang diharapkan, dan menjalin silaturahmi yang baik sehingga motivasi kerjanya sangat puas bagi karyawan.

\section{Kesimpulan}

Berdasarkan hasil dari penelitian dapat disimpulkan bahwa dokumen arsip dikantor BPJS Ketenagakerjaan Cabang Meulaboh belum tertata sesuai dengan susunannya, dan masih banyak karyawan yang meganggap kearsipan itu tidak terlalu penting sehingga arsip ini tidak terlalu diperhatikan dikarenakan kurangnya kesadaran dari karyawan. Pengelolaan arsip dikantor BPJS Ketenagakerjaan Cabang Meulaboh memakai tiga sistem yaitu sistem manual, sistem digitalisasi dan sistem terbaru yang melalui pengaplikasian.

Terdapat beberapa faktor yang memberikan pengaruh terhadap digitalisasi dalam efektifitas pengelolaan kearsipan dokumen terkait pemahaman dan pelaksanaan semua aturan dan kebijakan yang disediakan, juga memahami sarana dan prasarana serta fasilitas kantor yang cukup dan waktu yang tepat untuk memeriksa dan menguji kemampuan digitalisasi petugas arsip pada kantor BPJS Ketenaga Kerjaan. 


\section{BIBLIOGRAFI}

As'ad, M. (2012). Phsikologi Industri. Yogyakarta: Liberity Google Scholar

Bahri, S., \& Chairatun Nisa, Y. (2017). Pengaruh Pengembangan Karir Dan Motivasi Kerja Terhadap Kepuasan Kerja Karyawan. Jurnal Ilmiah Manajemen Dan Bisnis, 18(1), 9-15. https://doi.org/10.30596/jimb.v18i1.1395 Google Scholar

Faruk, G., \& Almahdi, S. (2020). Pengelolaan Sistem Kearsipan Elektronik Sebagai Determinan Produktivitas Kerja Pegawai di Kecamatan Solokuro Kabupaten Lamongan. 8(2016), 295-304. Google Scholar

Hasibuan, Malayu. 2003. Manajemen Sumber Daya Manusia. Jakarta: Bumi Aksara. Google Scholar

Kuswantoro, A.-, \& Hartati, S. H. (2019). Pengaruh Kompetensi Pegawai dan Sarana Prasarana Kearsipan Terhadap Pengelolaan Arsip Dinamis di Kantor Kelurahan Se-Kecamatan Gunungpati Kota Semarang. Khazanah: Jurnal Pengembangan Kearsipan, 12(2), 171. https://doi.org/10.22146/khazanah.48843 Google Scholar

Mellaty. (2015). Pengaruh Pengelolaan Arsip Klaim Peserta Jaminan Sosial Terhadap Ketersediaan Informasi Bagi Pengguna Di BPJS Ketenagakerjaan Semarang I. Vol. 4, No. 2. Google Scholar

Peraturan Pemerintah Pasal 17 menyebutkan Fungsi Anggaran DPRK diwujudkan dalam bentuk pembahasan rencana Qanun Google Scholar

Prapita imadianti.2010. Pencitraan Digital khasanah Arsip ANRI untuk JIKN (Jaringan Informasi Kearsipan Nasional).Depok : Universitas Indonesia. http://lib.ui.ac.id/file?file=pdf/abstrak-20161018.pdf (Diakses pada tanggal 15 Oktober 2018)

Santika, P., Yusuf, M. Y., \& Amri, A. (2018). Ekobis: Jurnal Ekonomi dan Bisnis Syariah Faktor-Faktor Yang Mempengaruhi Motivasi Kerja Karyawan Pada BPJS Ketenagakerjaan Cabang Banda Aceh Menurut Perspektif Ekonomi Islam. Google Scholar

First publication right:

Jurnal Syntax Fusion: Jurnal Nasional Indonesia

This article is licensed under:

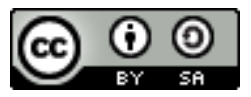

